\begin{tabular}{|c|l|}
\hline Title & PTHrP promotes malignancy of human oral cancer cell downstream of the EGFR signaling \\
\hline Author(s) & Y amada, Tamaki; Tsuda, Masumi; Ohba, Y usuke; Kawaguchi, Hideaki; Totsuka, Y asunori; Shindoh, Masanobu \\
\hline Citation & $\begin{array}{l}\text { Biochemical and Biophysical Research Communications, 368(3), 575-581 } \\
\text { https://doi.org/10.1016j.bbrc.2008.01.121 }\end{array}$ \\
\hline Issue Date & 2008-04_11 \\
\hline Doc URL & http://hdl.handle.net/2115/54567 \\
\hline Type & article(author version) \\
\hline File Information & Biochem Biophys Res Commun_368(3)_575-581.pdf \\
\hline
\end{tabular}

Instructions for use 


\title{
PTHrP promotes malignancy of human oral cancer cell downstream of the EGFR signaling
}

\author{
Tamaki Yamada ${ }^{\mathrm{a}, \mathrm{b}, \mathrm{c}}$, Masumi Tsuda ${ }^{\mathrm{a}}$, Yusuke Ohba ${ }^{\mathrm{a}, *}$, Hideaki Kawaguchi ${ }^{\mathrm{a}}$, \\ Yasunori Totsuka ${ }^{\mathrm{c}}$, Masanobu Shindoh ${ }^{\mathrm{b}}$
}

${ }^{a}$ Laboratory of Pathophysiology and Signal Transduction, Department of Pathology, Hokkaido University Graduate School of Medicine, Sapporo 060-8638, Japan

${ }^{\mathrm{b}}$ Division of Oral Pathobiological Science and ${ }^{\mathrm{c}}$ Laboratory of Oral and Maxillofacial Surgery, Hokkaido University Graduate School of Dental Medicine, Sapporo 060-8586, Japan

*Corresponding author. Fax: +81-11-706-7877.

E-mail address: yohba@med.hokudai.ac.jp 


\begin{abstract}
Parathyroid hormone-related protein $(\mathrm{PTHrP})$ is detected in many aggressive tumors and involved in malignant conversion; however, the underlying mechanism remains obscure. Here, we identified PTHrP as a mediator of epidermal growth factor receptor (EGFR) signaling to promote the malignancies of oral cancers. PTHrP mRNA was abundantly expressed in most of the quiescent oral cancer cells, and was significantly upregulated by EGF stimulation via ERK and p38 MAPK. PTHrP silencing by RNA interference, as well as EGFR inhibitor AG1478 treatment, significantly suppressed cell proliferation, migration, and invasiveness. Furthermore, combined treatment of AG1478 and PTHrP knockdown achieved synergistic inhibition of malignant phenotypes. Recombinant PTHrP substantially promoted cell motility, and rescued the inhibition by PTHrP knockdown, suggesting the paracrine/autocrine function of PTHrP. These data indicate that PTHrP contributes to the malignancy of oral cancers downstream of EGFR signaling, and may thus provide a therapeutic target for oral cancer.
\end{abstract}

Key words: PTHrP; EGFR; AG1478; RNA interference; oral cancer; therapeutics 


\section{Introduction}

Oral squamous cell carcinoma (OSCC) is a prevalent malignant tumor in the head and neck and shows marked local invasiveness. OSCC invasion into the adjoining bones is of major clinical concern. Specifically, carcinomas in lower gingiva and the floor of the mouth are frequently associated with mandibular invasion. Patient quality of life is substantially impaired by mandibulectomy and the development of potent therapeutics suppressing OSCC invasion is therefore strongly desired.

Parathyroid hormone-related protein (PTHrP) was originally identified as a major factor responsible for humoral hypercalcemia in malignancies [1], and acts classically as a stimulator of osteoclastic bone resorption [2]. PTHrP is produced by some malignant tumors, and involved in malignant conversion of breast, colon, and prostate cancer by increasing cell proliferation, survival, adhesion, migration, and invasion [3]. Several studies have examined the role of tumor growth factor- $\beta 1$ (TGF- $\beta 1$ ) and epidermal growth factor (EGF) signaling in the PTHrP gene expression in keratinocytes and lung cancer cells $[4,5]$.

EGF is enriched in the oral environment, and most OSCC cells express abundant EGF receptor (EGFR) [6]. EGFR, an ErbB family receptor tyrosine kinase, is constitutively activated by overexpression or mutations in a range of solid tumors. The phosphorylation of EGFR in the catalytic domain facilitates malignant conversion via uncontrolled cell proliferation, prevention of apoptosis, and increased cell migration. To date, pharmacological inhibitors of EGFR have been developed, and are currently under clinical investigation. EGFR-tyrosine kinase inhibitors (TKIs) including gefitinib and erlotinib efficiently block EGFR activation in vitro, and significantly inhibit tumor growth in experimental models. However, a phase III survival trial failed to verify the clinical benefit of gefitinib treatment for non-small cell lung cancer patients. 
The expression of PTHrP mRNA is detected in an established oral cancer cell line [7]. However, the regulatory mechanism of induction of PTHrP and its subsequent contribution to malignant conversion have not yet been elucidated in OSCC. Here, we utilized five independent human OSCC cell lines to provide evidence that PTHrP is up-regulated by EGFR signaling, and produces various aspects of malignant conversion of OSCC. The functional inhibition of EGFR by AG1478, PTHrP depletion by RNA interference (RNAi), and combined application of these reagents dramatically abolished the malignant phenotypes. These findings highlight both PTHrP and EGFR as attractive therapeutic targets in OSCC. 


\section{Materials and methods}

Cell culture, reagents, and antibodies. The detailed information on the cells, reagents, and antibodies are provided in supplementary data.

$\boldsymbol{R N A}$ isolation and $\boldsymbol{R T}$-PCR. Total RNA was isolated from cells using the RNeasy Mini Kit (QIAGEN, Valencia, CA, USA) according to the manufacturer's instructions. First strand cDNA was synthesized from $3.5 \mu \mathrm{g}$ of total RNA by SuperScript III reverse transcriptase (Invitrogen, Carlsbad, CA, USA). Real-time RT-PCR was performed using Light Cycler 480 and the Universal Probe Library system (Roche, Basal, Switzerland). The sequences for primers were described in supplementary data. The number of amplification cycles of conventional RT-PCR is indicated in the Figure Legends. Expression of $P T H r P$ was normalized to that of GAPDH.

Immunoblotting. Cells were lysed in lysis buffer [10 mM Tris-HCl (pH 7.4), 5 mM EDTA, 150 $\mathrm{mM} \mathrm{NaCl}, 10 \%$ glycerol, $1 \%$ Triton X-100, 1\% DOC, 0.1\% SDS, $50 \mathrm{mM} \mathrm{NaF}, 1 \mathrm{mM} \mathrm{NaVO}$, and complete (EDTA-free) protease inhibitor (Roche, Indianapolis, IN, USA)] for 20 min on ice and clarified by microcentrifugation. Supernatants were subjected to SDS-PAGE, and separated proteins were transferred to polyvinylidene difluoride membranes (Bio-Rad, Hercules, CA, USA). The membranes were incubated with primary antibodies, followed by peroxidase-labeled secondary antibodies. Signals were developed by ECL Western Blotting Detection Reagent (GE Healthcare, Little Chalfont, UK) and detected using an LAS-1000UVmini image analyzer (FUJIFILM, Tokyo, Japan).

Transfection with siRNA targeting PTHrP $\boldsymbol{m} R \boldsymbol{R} A$. Small interfering RNAs (siRNA) targeting PTHrP mRNA (siPTHrP) were obtained from QIAGEN and transiently transfected using the HiPerFect reagent (QIAGEN) according to the manufacturer's instructions. AllStars Negative 
Control siRNA (siControl, QIAGEN) was used as a control. After $48 \mathrm{~h}$ or $72 \mathrm{~h}$, the cells were subjected to analyses after the determination of expression levels of PTHrP mRNA by RT-PCR.

Measurement of cell proliferation, motility, and invasiveness. To measure the cell proliferation, $5 \times 10^{4}$ cells were plated onto $60 \mathrm{~mm}$ plates, and counted every other day for 8 days using a hematocytometer. To analyze the cell motility, confluent HSC-2 cells were wounded by scraping with a P200 pipette tip. Cell movements were observed by phase-contrast microscopy. The invasion assay was performed using 24-well BD BioCoat Matrigel Invasion Chambers (BDDiscovery Labware, Bedford, MA, USA). In the upper chamber, 2 x $10^{4} \mathrm{HSC}-2$ cells were seeded in complete DMEM medium. After $22 \mathrm{~h}$, the non-invading cells on the upper surface of the filters were removed by wiping with a cotton swab. Infiltrated cells were fixed with $3.7 \%$ formaldehyde in PBS, stained with 5\% crystal violet, and quantified. In some experiments, the similar experiments were performed in the presence or absence of AG1478. 


\section{Results}

\section{Human oral cancer cells express PTHrP}

PTHrP has been detected in many tumors, particularly breast and prostate [2]. In this study, we first examined the levels of $P T H r P$ by RT-PCR in five independent human OSCC cell lines: SAS, Ca9-22, HSC-2, HSC-3, and HSC-4. PTHrP mRNA was detected in all cell lines except SAS cells, but not in normal human gingival fibroblasts (HGF-1), and was highest in HSC-2 and HSC-4 cells (Fig. 1A). PTHrP protein levels were examined by immunoblotting (Fig. 1B) and immunofluorescence (data not shown), and in parallel with mRNA levels. PTHrP expression in OSCC was substantially higher than in other types of highly bone-metastatic tumor cells including prostate cancers (PC-3 and LNCap), osteosarcoma (Saos-2), and synovial sarcoma (SYO-1) (Fig. 1C). Of note, since these cell lines have been reported to express abundant PTHrP, the expression level in OSCC appeared exceedingly high, indicating the potential role for PTHrP in the development of OSCC.

\section{EGF induces PTHrP expression via ERK1/2 and p38 MAPK in OSCC}

OSCC arising from the EGF-enriched oral environment express abundant EGFR [6], suggesting that EGF-EGFR signaling is associated with the malignant biology of this cancer. We hypothesized that activation of EGFR signaling was correlated to enhanced $\mathrm{PTHrP}$ expression and subsequent malignant conversions in OSCC. The summary of the properties of EGFR in the OSCC cell lines used here was as follows: OSCCs expressed abundant EGFR (Supplementary Fig. 1A); EGFR was predominantly localized to the plasma membrane in the quiescent state (Supplementary Fig. 1B); The phosphorylation on Tyr1173, the direct binding site for SHC, SHP1, and PLC- $\gamma$, was readily detectable in OSCCs even without EGF stimulation, but not in A431 epidermoid carcinoma cells (Supplementary Fig. 1C); none of the cell lines 
possessed any mutations in the catalytic domain and C-terminal docking sites (data not shown); EGF stimulation significantly increased the EGFR phosphorylation (Supplementary Fig. 1C).

We investigated the role of EGFR activation in $\mathrm{PTHrP}$ expression, and found that EGF stimulation induced PTHrP expression in HSC-2, HSC-3, HSC-4, and Ca9-22 cells by RT-PCR and Quantitative real-time RT-PCR (Fig. 2A and Supplementary Fig. 2A-B). PTHrP mRNA was approximately 1.7-fold higher following EGF stimulation of HSC-2 cells (Fig. 2A). The effect of EGF on PTHrP expression seems to be limited probably due to high basal levels of EGFR phosphorylation (Supplementary Fig. 1C) and PTHrP expression (Fig. 1A-C). Indeed, the EGFR-TKI AG1478 reduced PTHrP expression to extremely lower than the basal level (Fig. 2B and supplementary Fig. 2C).

Next, we investigated the downstream pathway contributed to the expression of PTHrP. Immunoblotting analyses using phosphorylation site-specific antibodies revealed EGF-dependent phosphorylation of ERK1/2, p38 MAPK, and SAPK/JNK in HSC-2 cells (Fig. 2C). Among these MAPKs, ERK and p38 MAPK appeared to mediate EGF-dependent PTHrP expression, since the ERK inhibitor U0126 and p38 MAPK inhibitor SB203580, but not the JNK inhibitor SP600125, reduced EGF-induced PTHrP expression (Fig. 4D). These data indicate that EGFR and the ERK and p38 MAPK cascades are primary regulators of PTHrP expression in OSCC.

To further clarify the relationship between the EGFR-MAPK signaling and PTHrP expression, we examined the effects of AG1478 and U0126 on EGF-stimulated MAPK cascades and subsequent PTHrP expression. These reagents suppressed target molecules in a dose dependent manner as expected (Supplementary Fig. 3A-C). Interestingly, U0126 treatment in combination with AG1478 produced an additive effect on the inhibition of ERK1/2 phosphorylation (Supplementary Fig. 4D). Concomitantly with this ERK1/2 suppression, 
combined treatment of HSC-2 cells with AG1478 and U0126 most effectively suppress the PTHrP expression (Fig. 2E). Taken together, the EGFR-MAPK cascades are profoundly involved in the PTHrP expression in OSCC.

\section{$P T H r P$ regulates malignant phenotypes in $\mathrm{OSCC}$}

To examine whether PTHrP accelerates the development of malignant phenotypes of OSCC, we thus utilized RNAi to knockdown endogenous PTHrP and investigated its effects on cell proliferation, migration, and invasion. $\mathrm{PTHrP}$-targeted siRNA (siPTHrP) transfection significantly decreased $P T H r P$ gene expression, by $70 \%, 80 \%$, and 60\% in HSC-2, HSC-4, and HSC-3 cells, respectively, when compared with a scrambled control siRNA (siControl), whereas GAPDH gene expression was not altered by siRNA transfection (Fig. 3A and supplementary Fig. 4A). Expression of PTHrP protein was also suppressed by siPTHrP (Fig. 3B). Under these conditions, we evaluated the effects of PTHrP on cell proliferation, motility, and invasion. The elimination of PTHrP resulted in approximately $40 \%$ reduction in cell proliferation of HSC-2 cells (Fig. 3C). Wound-healing assays demonstrated that cell motility with PTHrP silencing was decreased compared to siControl (Fig. 3D). Furthermore, siPTHrP transfection significantly reduced Matrigel invasion of HSC-2 cells (Fig. 3E, P < 0.005). Similar results were obtained in HSC-3 cells (Supplementary Figure 4B-D). These data collectively suggest that PTHrP contributes to the malignant phenotypes of OSCCs.

To gain further insight into the mechanisms by which PTHrP regulates OSCC malignancy, we examined the effects of PTHrP silencing on MAPK and phosphatidylinositol 3kinase (PI3K)/Akt signaling, which are involved in cell proliferation, survival, and motility. The phosphorylations of ERK1/2 and Akt at Ser473 were reduced in PTHrP-silenced HSC-2 cells 
compared to control cells, whereas phosphorylation of Akt at Thr308, in addition to the total expression levels, was not affected (Fig. 3F or data not shown).

Next, we investigated the expression level of PTH/PTHrP receptor PTH1R, and noticed that three OSCCs expressed PTH1R at a similar level of Saos-2, which is reported to express abundant PTH1R [8] (Fig. 3G). This observation raises the possibility that PTHrP functions in a paracrine/autocrine manner via PTH1R in OSCCs. In fact, exogenous PTHrP stimulation induced substantial phosphorylations of ERK1/2 and Akt in HSC-2 cells (Fig. 3H). In addition, PTHrP enhanced cell motility, and completely rescued the suppression by siPTHrP (Fig. 3I). On the other hand, Matrigel invasiveness was slightly increased in the presence of exogenous PTHrP (Fig. 3J). Taken together, in OSCCs, PTHrP functions via cell surface PTH1R at least in part.

\section{Synergetic effects of AG1478 and PTHrP knockdown on cell proliferation and invasion}

Currently, the EGFR signaling is one of the most frequently targeted pathways for caner therapy; however, the therapy are well tolerated and have reproducible and unique toxicities, which often require dose interruptions or reductions. When we examined the effect of EGFR and MAPK inhibitors on cell proliferation, motility, and invasion of HSC-2 cells, essentially similar results were obtained as those of siPTHrP, except that p38 MAPK inhibitor enhanced cell proliferation (Supplementary Fig. 5, 6). Therefore, to evaluate the possibility of combination of EGFR-TKI and PTHrP suppression for therapeutics, we finally investigated whether the combination exhibit synergistic effects on OSCC malignancy. Treatment of AG1478 in PTHrPdepleted HSC-2 cells most completely inhibited cell proliferation of HSC-2 cells (Fig. 4A).

Furthermore, the combination produced an additive effect on Matrigel invasiveness, reducing by 75\% (Fig. 4B). These results may offer the dual targeting to EGFR and PTHrP as a potent novel therapeutics against OSCCs. 


\section{Discussion}

Enhanced cell migration, invasion, and uncontrolled cell growth are crucial components for tumor progression, and, indeed, OSCC have a high potential for invasiveness, frequently targeting the mandibular bone. In this study, we used five OSCC cell lines to explore the role of EGFR signaling in PTHrP expression, in the context of OSCC invasiveness. EGF signaling upregulates $P T H r P$ gene expression through the MAPK cascades, which lead to malignant conversion of OSCC by enhanced cell proliferation, migration, and invasion. In addition, the inhibition of EGFR by AG1478, depletion of PTHrP by RNAi, and the combination of them dramatically suppressed the malignant potential of OSCC.

PTHrP expression is regulated by various humoral factors including TGF- $\beta 1$ and EGF, which is expressed in cancer cells, and can increase transcription and stability of $P T H r P$ mRNA, and secretion of the protein $[9,10]$. Our study clearly identified that EGF, but not TGF- $\beta \square 1$, mediated transcriptional activation of PTHrP in OSCC (Fig. 2 or data not shown), indicating the cell type-specific regulation of $P T H r P$ expression. Despite the lack of mutations, EGFR was phosphorylated to some extent in unstimulated OSCC (Supplementary Fig. 1C), suggesting the autocrine production of EGFR ligands to constitutively activate EGFR and to dictate high levels of PTHrP (Fig. 1C). Alternatively, EGFR overexpression may cause transactivation of EGFR in a ligand-independent manner.

We showed that EGF activated ERK, p38 MAPK, and JNK in OSCC. Among them, ERK and p38 MAPK were involved in PTHrP expression. Both kinases are known to activate a distinct set of transcriptional factors and subsequent gene induction to contribute tumor progression $[11,12]$. Several transcription factors have been implicated in $P T H r P$ expression $[13,14]$. Although high levels of Ets1 were detected in OSCC (unpublished result), we found no 
specific involvement of Ets1 in $\mathrm{PTHrP}$ expression by chromatin immunoprecipitation assay (data not shown). Thus, further detailed analyses will be required to clarify the transcription factors responsible for $\mathrm{PTHrP}$ expression in OSCC.

We found that phosphorylation of ERK and Akt was decreased in PTHrP-silenced HSC2 cells (Fig. 3F). Furthermore, exogenous PTHrP stimulation induced ERK and Akt phosphorylation. PTHrP may functions, at least partly, in a paracrine/autocrine manner via PTH1R in OSCC (Fig. 3G-J). Recently, it is reported that PTHrP translocates into the nucleus and functions in an intracrine manner, which is associated with altered cell-cycle progression and protection from apoptosis [15-17]. We noted nuclear localization of PTHrP in addition to a cytoplasmic signal; however, PTHrP may not participate in apoptotic pathways in OSCC, since we found no cleaved Caspase-3, -9, or PARP in cells deficient in PTHrP (data not shown). The other intracrine functions of PTHrP seem to be connected to cell adhesiveness and motility through integrin expression and actin reorganization $[3,18,19]$. In this study, we showed that stimulation by recombinant PTHrP significantly promoted cell motility, whereas the effect on invasiveness was marginal (Fig. 3I, J). It is possible that PTHrP regulates the OSCC motility and invasiveness by different manners: the autocrine and intracrine pathways, respectively. Thus, PTHrP may coordinately enhance cell proliferation and invasiveness of OSCC through autocrine, paracrine, and intracrine signaling (Fig. 4C).

Targeting PTHrP in preclinical settings has been attempted using a neutralizing antibody, antisense oligonucleotides, and RNAi, which resulted in prolonged survival of hypercalcemic mice, decreased cell proliferation of renal carcinoma, and increased apoptosis in human medulloblastomas, respectively [20-22]. We also demonstrated the inhibitory effects of siPTHrP on cell proliferation and motility of OSCC. Moreover, PTHrP knockdown with AG1478 
treatment exhibited more effective suppression on cell proliferation and invasiveness, even with the lower dose of AG1478 (Fig. 4A, B). Our results suggest the fascinating possibility that the combined application of PTHrP on dose-reduction of EGFR-TKI may contribute to avoid the EGFR-TKI-derived adverse aspects, and to maintain the anti-malignant potency. We therefore strongly propose targeting both EGFR and PTHrP in anticipation of their synergistic effects, which could lead to the conquest of oral cancer. 


\section{Acknowledgements}

We thank S. Tanaka for use of the confocal laser-scanning microscope, J. Hamada for a facility for cells, A. Kawai for providing SYO-1 cells, T. Watanabe for providing antibodies, N. Toyoda for technical assistance, and members of our laboratories for helpful discussions. This work was supported in part by Grants-in-Aid for Young Scientists from MEXT, Japan, and for Exploratory Research from JSPS. 


\section{References}

[1] W. J. Burtis, T. G. Brady, J. J. Orloff, J. B. Ersbak, R. P. Warrell, Jr., B. R. Olson, T. L. Wu, M. E. Mitnick, A. E. Broadus, A. F. Stewart, Immunochemical characterization of circulating parathyroid hormone-related protein in patients with humoral hypercalcemia of cancer, $\mathrm{N}$ Engl J Med 322 (1990) 1106-1112.

[2] J. Liao, L. K. McCauley, Skeletal metastasis: Established and emerging roles of parathyroid hormone related protein (PTHrP), Cancer Metastasis Rev 25 (2006) 559-571.

[3] X. Shen, L. Qian, M. Falzon, PTH-related protein enhances MCF-7 breast cancer cell adhesion, migration, and invasion via an intracrine pathway, Exp. Cell Res. 294 (2004) 420433.

[4] Y. M. Cho, D. A. Lewis, P. F. Koltz, V. Richard, T. A. Gocken, T. J. Rosol, R. L. Konger, D. F. Spandau, J. Foley, Regulation of parathyroid hormone-related protein gene expression by epidermal growth factor-family ligands in primary human keratinocytes, J. Endocrinol. 181 (2004) 179-190.

[5] G. Lorch, J. L. Gilmore, P. F. Koltz, R. M. Gonterman, R. Laughner, D. A. Lewis, R. L. Konger, K. S. Nadella, R. E. Toribio, T. J. Rosol, J. Foley, Inhibition of epidermal growth factor receptor signalling reduces hypercalcaemia induced by human lung squamous-cell carcinoma in athymic mice, Br. J. Cancer (2007).

[6] R. Todd, D. T. Wong, Epidermal growth factor receptor (EGFR) biology and human oral cancer, Histol Histopathol 14 (1999) 491-500.

[7] T. Nomura, T. Shibahara, A. Katakura, S. Matsubara, N. Takano, Establishment of a murine model of bone invasion by oral squamous cell carcinoma, Oral Oncol 43 (2007) 257-262.

[8] S. Fukayama, E. Schipani, H. Juppner, B. Lanske, H. M. Kronenberg, A. B. Abou-Samra, F. R. Bringhurst, Role of protein kinase-A in homologous down-regulation of parathyroid hormone (PTH)/PTH-related peptide receptor messenger ribonucleic acid in human osteoblast-like SaOS-2 cells, Endocrinology 134 (1994) 1851-1858.

[9] J. K. Heath, J. Southby, S. Fukumoto, L. M. O'Keeffe, T. J. Martin, M. T. Gillespie, Epidermal growth factor-stimulated parathyroid hormone-related protein expression involves 
increased gene transcription and mRNA stability, Biochem. J. 307 (Pt 1) (1995) 159-167.

[10] R. S. Sellers, C. C. Capen, T. J. Rosol, Messenger RNA stability of parathyroid hormonerelated protein regulated by transforming growth factor-beta1, Mol. Cell. Endocrinol. 188 (2002) 37-46.

[11] P. J. Roberts, C. J. Der, Targeting the Raf-MEK-ERK mitogen-activated protein kinase cascade for the treatment of cancer, Oncogene 26 (2007) 3291-3310.

[12] C. Bradham, D. R. McClay, p38 MAPK in development and cancer, Cell Cycle 5 (2006) 824-828.

[13] J. A. Sterling, B. O. Oyajobi, B. Grubbs, S. S. Padalecki, S. A. Munoz, A. Gupta, B. Story, M. Zhao, G. R. Mundy, The hedgehog signaling molecule Gli2 induces parathyroid hormone-related peptide expression and osteolysis in metastatic human breast cancer cells, Cancer Res. 66 (2006) 7548-7553.

[14] M. Karperien, H. Farih-Sips, C. W. Lowik, S. W. de Laat, J. Boonstra, L. H. Defize, Expression of the parathyroid hormone-related peptide gene in retinoic acid-induced differentiation: involvement of ETS and Sp1, Mol. Endocrinol. 11 (1997) 1435-1448.

[15] N. Fiaschi-Taesch, B. M. Sicari, K. Ubriani, T. Bigatel, K. K. Takane, I. Cozar-Castellano, A. Bisello, B. Law, A. F. Stewart, Cellular mechanism through which parathyroid hormonerelated protein induces proliferation in arterial smooth muscle cells: definition of an arterial smooth muscle PTHrP/p27kip1 pathway, Circ. Res. 99 (2006) 933-942.

[16] A. Dittmer, M. Vetter, D. Schunke, P. N. Span, F. Sweep, C. Thomssen, J. Dittmer, Parathyroid hormone-related protein regulates tumor-relevant genes in breast cancer cells, J. Biol. Chem. 281 (2006) 14563-14572.

[17] L. E. Okoumassoun, C. Russo, F. Denizeau, D. Averill-Bates, D. J. Henderson, Parathyroid hormone-related protein (PTHrP) inhibits mitochondrial-dependent apoptosis through CK2, J. Cell. Physiol. 212 (2007) 591-599.

[18] X. Shen, M. Falzon, Parathyroid hormone-related protein upregulates integrin expression via an intracrine pathway in PC-3 prostate cancer cells, Regul. Pept. 113 (2003) 17-29.

[19] X. Deng, S. H. Tannehill-Gregg, M. V. Nadella, G. He, A. Levine, Y. Cao, T. J. Rosol, 
Parathyroid hormone-related protein and ezrin are up-regulated in human lung cancer bone metastases, Clin Exp Metastasis 24 (2007) 107-119.

[20] K. Sato, Y. Yamakawa, K. Shizume, T. Satoh, K. Nohtomi, H. Demura, T. Akatsu, N. Nagata, T. Kasahara, H. Ohkawa, Passive immunization with anti-parathyroid hormonerelated protein monoclonal antibody markedly prolongs survival time of hypercalcemic nude mice bearing transplanted human PTHrP-producing tumors, J. Bone Miner. Res. 8 (1993) 849-860.

[21] I. Talon, V. Lindner, C. Sourbier, E. Schordan, S. Rothhut, M. Barthelmebs, H. Lang, J. J. Helwig, T. Massfelder, Antitumor effect of parathyroid hormone-related protein neutralizing antibody in human renal cell carcinoma in vitro and in vivo, Carcinogenesis 27 (2006) 73-83.

[22] M. Gessi, G. Monego, G. Calviello, P. Lanza, F. Giangaspero, A. Silvestrini, L. Lauriola, F. O. Ranelletti, Human parathyroid hormone-related protein and human parathyroid hormone receptor type 1 are expressed in human medulloblastomas and regulate cell proliferation and apoptosis in medulloblastoma-derived cell lines, Acta Neuropathol (Berl) (2007). 


\section{Figure Legends}

Fig. 1. Expression of PTHrP in OSCC. (A) Expression levels of PTHrP were determined by RT-PCR at 23 cycles (upper columns). The intensity of the bands was quantified and normalized. The fold increase is shown at the bottom. (B) Levels of PTHrP protein in OCSS were analyzed by immunoblotting using a specific antibody. (C) Extremely high expression of PTHrP in OSCC. The expression levels in the indicated cell types were determined as in (A).

Fig. 2. EGF-induced PTHrP expression and its repression by AG1478, U0126, and SB203580. (A, B, D, E) HSC-2 cells were serum-starved for $16 \mathrm{~h}$, and were left untreated (A), treated with $1.0 \mu \mathrm{M}$ AG1478 for 3 or $6 \mathrm{~h}$ (B), $10.0 \mu \mathrm{M}$ U0126, $10 \mu \mathrm{M}$ SB203580, and 10.0 $\mu \mathrm{M}$ SP6001265 for 3 or $6 \mathrm{~h}$ (D), or $1.0 \mu \mathrm{M}$ AG1478 and/or 1.0 or $10.0 \mu \mathrm{M}$ U0126 for $3 \mathrm{~h}$ (E). The cells were then stimulated by $10 \mathrm{ng} / \mathrm{ml}$ EGF for 30 or 60 min except for the left lane. Levels of PTHrP were determined by quantitative real-time RT-PCR (A, B, E) and RT-PCR at 20 cycles (D). (C) HSC-2 cells were serum-starved for $16 \mathrm{~h}$, followed by treatment with $10 \mathrm{ng} / \mathrm{ml}$ EGF for the indicated times prior to lysis. Protein extracts were analyzed by immunoblotting with the antibodies indicated at the bottom of each column.

Fig. 3. PTHrP regulates OSCC malignancy. (A) HSC-2 cells were transfected with PTHrP siRNA (siPTHrP), or a scrambled siRNA (siControl). Levels of PTHrP were determined by RTPCR after $48 \mathrm{~h}$. (B) Levels of PTHrP protein were analyzed by immunoblotting after $72 \mathrm{~h}$. (C) Numbers of HSC-2 cells transfected with siPTHrP or siControl were counted over 7 days. (D) HSC-2 cells were transfected with siPTHrP or siControl. After $48 \mathrm{~h}$, the confluent cells were wounded, and subjected to time-lapse microscopy. (E) Matrigel invasion in HSC-2 cells transfected with siPTHrP or siControl was analyzed as described in the Materials and methods. *, P $<0.005$. (F) HSC-2 cells were transfected with siPTHrP or siControl. After $72 \mathrm{~h}$, 
expression levels and phosphorylation of ERK and Akt were analyzed by immunoblotting. (G) Expression levels of PTH1R in three OSCCs were analyzed by immunoblotting. Human osteosarcoma cell line Saos-2 was used as a positive control. (H) HSC-2 cells were serumstarved for $16 \mathrm{~h}$, and treated with $100 \mathrm{ng} / \mathrm{ml}$ PTHrP for the indicated times. Protein levels and phosphorylation of ERK and Akt were determined by immunoblotting. (I, J) Effects of exogenous PTHrP on cell motility (I) and Matrigel invasiveness (J). HSC-2 cells prepared as above were treated with or without $100 \mathrm{ng} / \mathrm{ml}$ PTHrP.

Fig. 4. (A, B) Synergistic effects of AG1478 and PTHrP knockdown. HSC-2 cells were transfected with siPTHrP or siControl. After $48 \mathrm{~h}$, the cells were treated with or without $0.04 \mu \mathrm{M}$ AG1478, and then subjected to the cell proliferation assay (A) or Matrigel invasion assay (B).

(C) Scheme of the PTHrP and EGFR signaling in OSCC. Activation of EGFR upregulates PTHrP expression via ERK and p38 MAPK. Highly expressed PTHrP binds to PTH1R in a paracrine/autocrine manner, activates ERK and Akt, and promotes OSCC malignancy. Solid and dashed lines indicate the pathways demonstrated in this study and have been described elsewhere, respectively. TFs, transcription factors. 


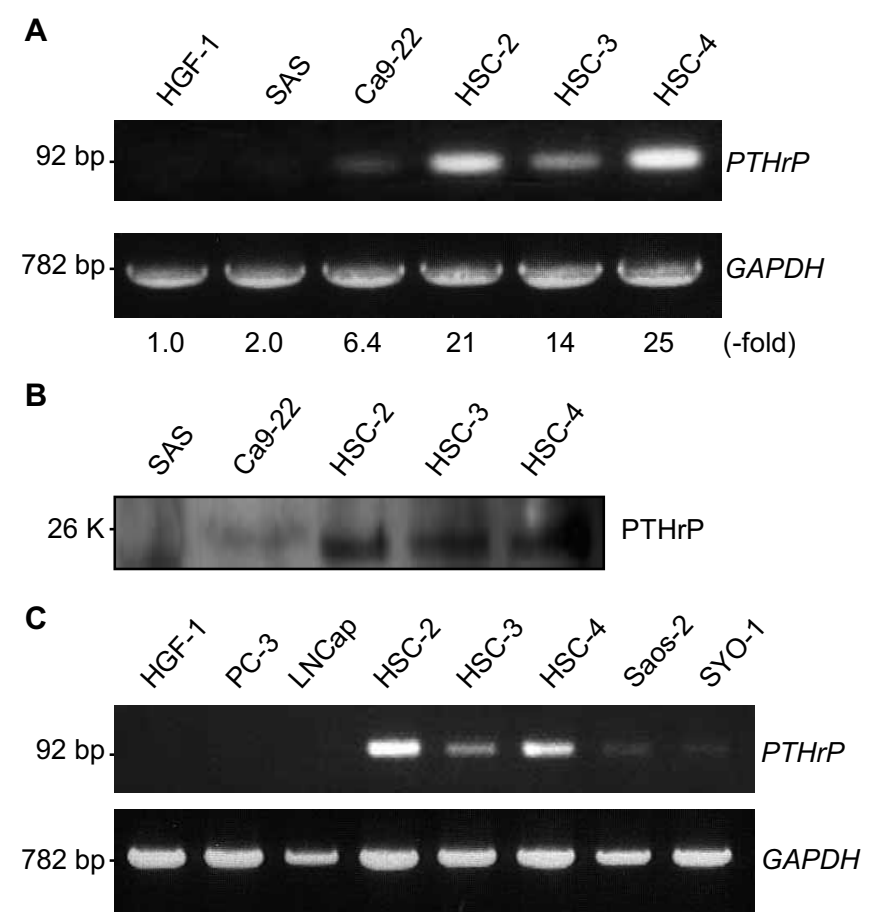

Fig. 1, Yamada et. al. 


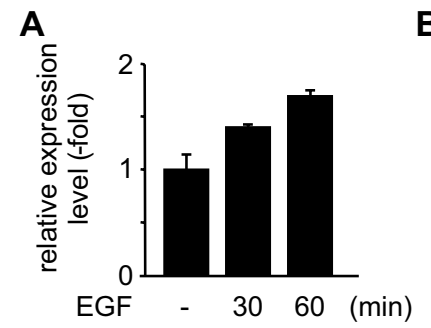

B

C
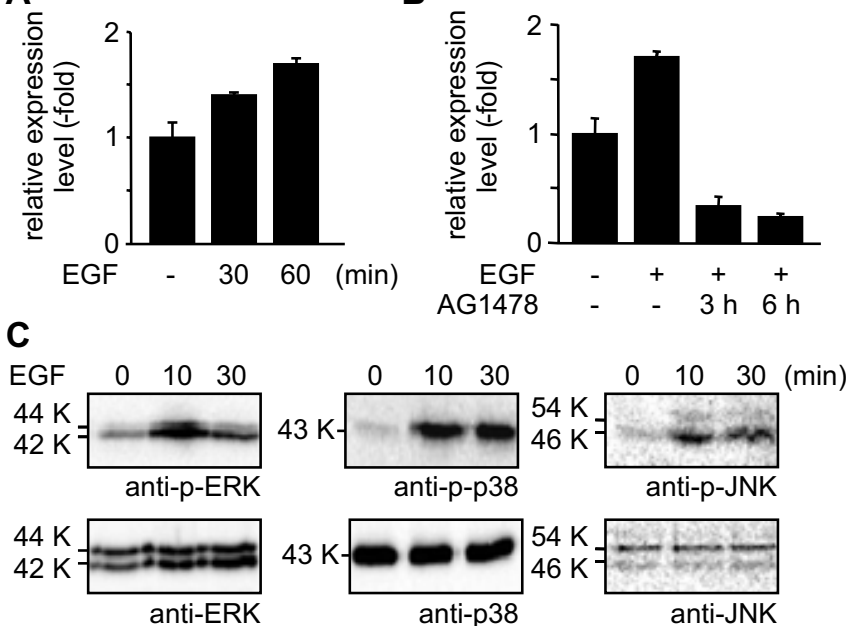

D

U0126 SB203580 SP600125

EGF - +++++

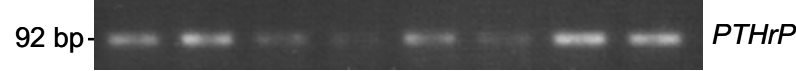

782 bp - ول

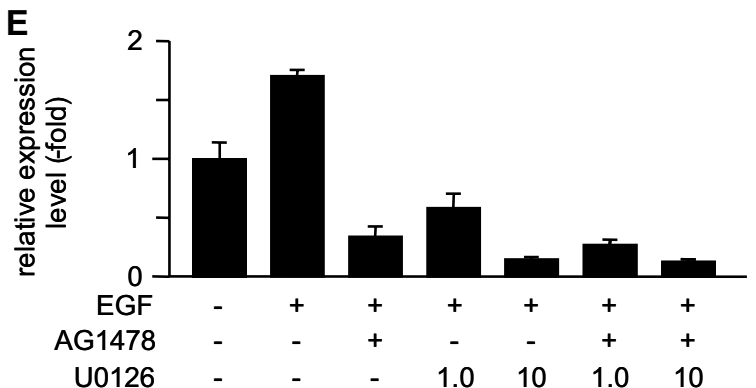

Fig. 2, Yamada et. al. 

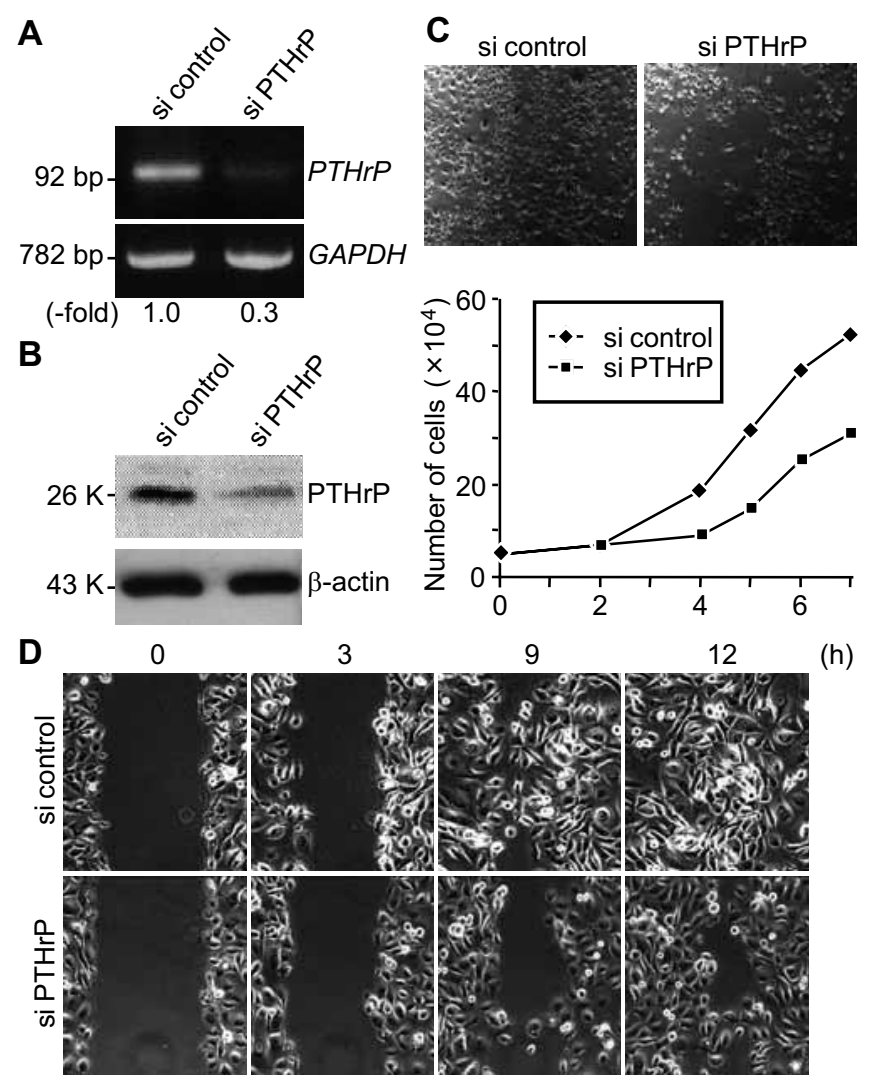

E
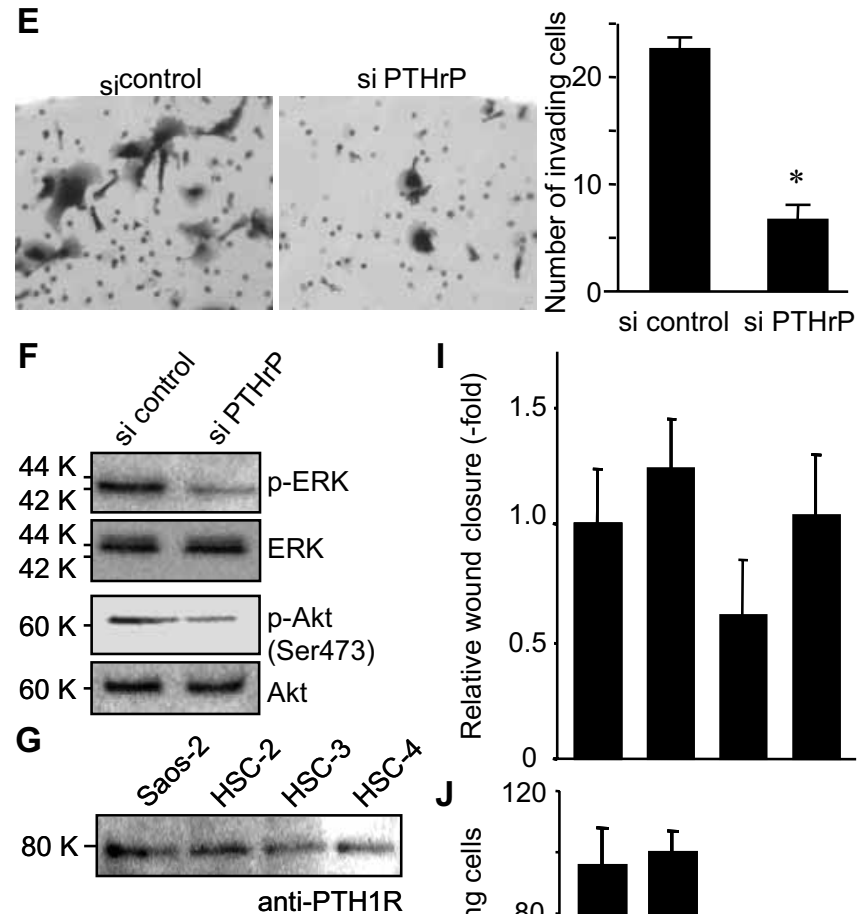

H
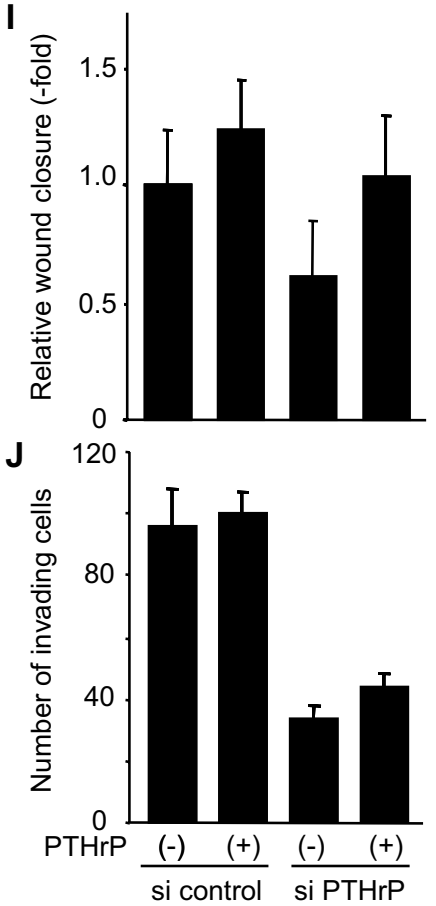

Fig. 3, Yamada et. al. 


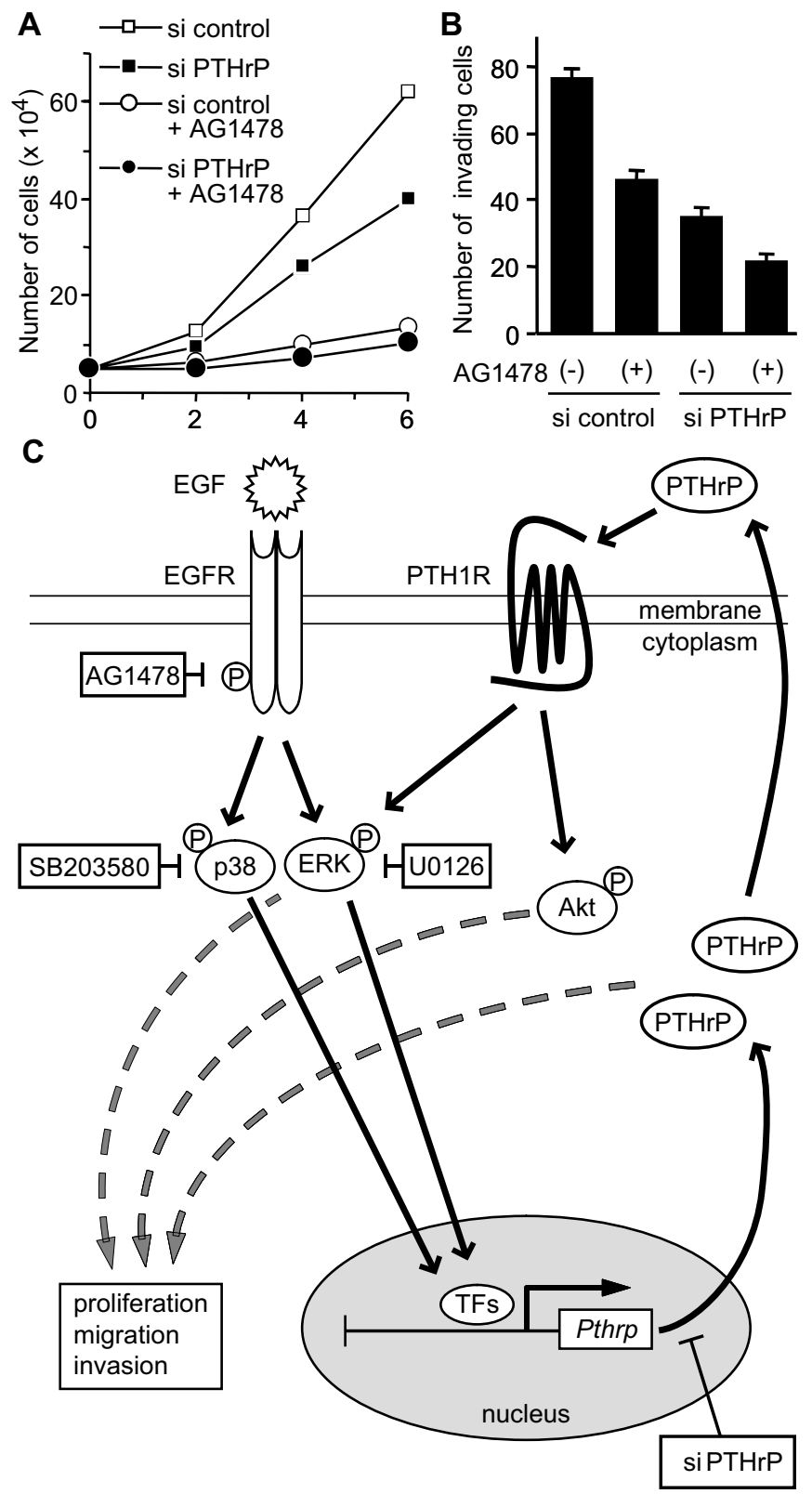

Fig. 4, Yamada et. al. 


\section{Appendix A Supplementary data}

\section{Supplementary Materials and methods}

Cell culture. Human oral squamous cell carcinoma cell lines SAS (JCRB0260), Ca9-22 (JCRB0625), HSC-2 (JCRB0622), HSC-3 (JCRB0623), and HSC-4 (JCRB0624) were obtained from the JCRB cell bank (Osaka, Japan). Human gingival fibroblasts (HGF-1, CRL-2014) and human prostate cancer cells (PC-3, CRL-1435; LNCaP clone FGC, CRL-1740) were purchased from the ATCC (Manassas, VA, USA). An SYO-1 human synovial sarcoma cell line [S1] was provided by A Kawai (National Cancer Center, Tokyo, Japan). All cells used in this study, with the exception of LNCaP cells, were maintained in Dulbecco's modified Eagle's medium (Sigma, St. Louis, MO, USA) supplemented with $10 \%$ fetal bovine serum (FBS) (Cansera, Canada). LNCaP cells were cultured in RPMI medium (Sigma) with 10\% FBS.

Reagents and antibodies. Polyclonal antibodies against ERK1/2, p38 MAP kinase, JNK/SAPK, Akt, phospho-ERK1/2 (Thr202/Tyr204), phospho-p38 MAPK (Thr180/Tyr182), phosphoJNK/SAPK (Thr183/Tyr185), and phospho-Akt (Ser473) were purchased from Cell Signaling Technology (Beverly, MA, USA). Anti-PTHrP (1-34)-NH2 and anti-PTH1R antibodies were obtained from Yanaihara (Shizuoka, Japan) and Santa Cruz Biotechnology (Santa Cruz, CA, USA), respectively. Human recombinant EGF and PTHrP peptide were obtained form PeproTech (Rocky Hill, NJ, USA). The inhibitors of EGFR, AG1478; MEK1/2, U0126; p38 MAPK, SB203580; JNK, SP600125 were from Calbiochem (San Diego, CA, USA).

Monoclonal antibodies against EGFR and $\beta$-actin were purchased from Sigma (Sigma, St. Louis, MO, USA); phospho-EGFR (Tyr1173) was purchased from Cell Signaling Technology (Beverly, MA, USA).

Sequences of primers and probes. The sequences of the primers for RT-PCR were as follows: human PTHrP forward, 5'-GTCCTAGCCGCCGCCTCAA-3', PTHrP reverse, 5'GGAAGAAT-CGTCGCCGTAAA-3' (amplification size 92 bp); human GAPDH forward, 5'GAAATCCCATCACCATCTTCCAGG-3', GAPDH reverse, 5'-CATGTGGGCCATGAGGTCCACCAC-3' (amplification size 782 bp).

The sequences for primers and probes for real-time RT-PCR were as follows: PTHrP forward, 5'-CTCGGTGGAGGGTCTCAG; $P$ THrP reverse, 5'-TGGATGGACTTCCCCTTGT; $P$ THrP 
probe, 5'-CAGCTCCT; GAPDH forward, 5'-AGCCACATCGCTCAGACAC; GAPDH reverse, 5'-GCCCAATACGACCAAATCC; GAPDH probe, 5'-TGGGGAAG.

Immunofluorescent staining of EGFR. Cells were fixed in 3\% paraformaldehyde for $15 \mathrm{~min}$ at room temperature (RT), permeabilized with $0.1 \%$ Triton X-100 in PBS for 4 min at RT, and then post-fixed with $70 \%$ methanol for $5 \mathrm{~min}$ at $-20^{\circ} \mathrm{C}$. Cells were incubated with $1 \%$ bovine serum albumin to block non-specific binding of antibodies. The cells were incubated with anti-EGFR mouse monoclonal antibody (1:500 dilution) at $4{ }^{\circ} \mathrm{C}$ overnight, and then with Alexa 488conjugated goat anti-mouse IgG (1:200 dilution, Molecular Probes, Invitrogen) for $1 \mathrm{~h}$ at RT in the dark. Fluorescent images were acquired using a confocal laser-scanning microscope (FV300; Olympus, Tokyo, Japan).

\section{Supplementary Reference}

[1] A. Kawai, N. Naito, A. Yoshida, Y. Morimoto, M. Ouchida, K. Shimizu, Y. Beppu, Establishment and characterization of a biphasic synovial sarcoma cell line, SYO-1, Cancer Lett 204 (2004) 105-113. 


\section{Supplementary Figure Legends}

Supplementary Fig. 1. OSCC cell lines express high levels of EGFR. (A) Protein extracts derived from five human OSCC and normal human gingival fibroblasts (HGF-1) were analyzed by immunoblotting with anti-EGFR and anti- $\beta$-actin. (B) Immunofluorescence analysis of EGFR localization in human OSCC. The cells were stained with anti-EGFR as described in the Materials and Methods. (C) Human OSCC and human epidermoid carcinoma A431 were serumstarved for $16 \mathrm{~h}$, followed by treatment with $10 \mathrm{ng} / \mathrm{ml}$ EGF for the indicated times prior to lysis. Protein extracts were analyzed by immunoblotting with anti-phospho-EGFR (Y1173) and antiEGFR.

Supplemental Fig. 2. (A) HSC-2 cells were serum-starved for $16 \mathrm{~h}$, and stimulated by $10 \mathrm{ng} / \mathrm{ml}$ EGF for 30 or $60 \mathrm{~min}$ as indicated. (B) EGF induced transcriptional activation of PTHrP in OSCC. Expression levels of PTHrP were determined by RT-PCR, as in (A). (C) HSC-2 cells were serum-starved for $16 \mathrm{~h}$, and treated with $1.0 \mu \mathrm{M}$ AG1478 for 3 or $6 \mathrm{~h}$, and stimulated by 10 $\mathrm{ng} / \mathrm{ml}$ EGF. (D) HSC-2 cells were serum-starved for $16 \mathrm{~h}$, and treated with $1.0 \mu \mathrm{M}$ AG1478 and/or 1.0 or $10.0 \mu \mathrm{M}$ U0126 for $3 \mathrm{~h}$, and stimulated by $10 \mathrm{ng} / \mathrm{ml}$ EGF.

Supplementary Fig. 3. The EGFR inhibitor AG1478 inhibits EGF-dependent EGFR phosphorylation and downstream signaling. (A) HSC-2 cells were pretreated with EGFR inhibitor AG1478 at the indicated doses for $3 \mathrm{~h}$, followed by stimulation with $10 \mathrm{ng} / \mathrm{ml}$ EGF for 30 min. Protein extracts were analyzed by immunoblotting using the indicated antibodies. (B) AG1478 inhibited EGF-evoked phosphorylation of EGFR in OSCC cell lines in a dosedependent manner. Cell lines indicated at the left were pretreated with AG1478, stimulated by EGF, and lysed in lysis buffer. The resulting cell lysates were processed as in (A). (C) HSC-2 cells were treated with the MEK1/2 inhibitor U0126 at the indicated doses for $3 \mathrm{~h}$, followed by $10 \mathrm{ng} / \mathrm{ml}$ EGF stimulation for $30 \mathrm{~min}$. Protein extracts were analyzed by immunoblotting using anti-ERK1/2 and anti-phospho-ERK1/2 (T202/Y204). (D) HSC-2 cells were pretreated with 1.0 $\mu \mathrm{M}$ AG1478 together with 1.0 or $10.0 \mu \mathrm{M}$ U0126 for $3 \mathrm{~h}$, as indicated, followed by treatment with $10 \mathrm{ng} / \mathrm{ml}$ EGF for $30 \mathrm{~min}$. Protein levels and phosphorylation of EGFR and ERK1/2 were determined by using specific antibodies.

Supplementary Fig. 4. PTHrP depletion suppresses cell proliferation, motility, and invasion of OSCCs. (A) Levels of PTHrP mRNA were determined by RT-PCR at 48 and 72 h post- 
transfection. (B) Effect of PTHrP depletion on cell proliferation in HSC-3 cells. (C) Analysis of cell motility by wound healing assay in HSC-3 cells. (D) Matrigel invasion in HSC-3 cells. Supplementary Fig. 5. AG1478 and U0126 inhibit cell proliferation, motility, and Matrigel invasion in HSC-2 cells. (A) Proliferation of HSC-2 cells in the presence of $1.0 \mu \mathrm{M}$ AG1478 was examined every other day over 8 days. DMSO was used for control treatments. (B) Analysis of cell motility by wound-healing assays. Confluent HSC-2 cells were wounded by scraping with a pipette tip, and then incubated in the presence or absence of $1.0 \mu \mathrm{M}$ AG1478 for an additional $24 \mathrm{~h}$. Images were acquired every $3 \mathrm{~min}$ after wounding, and selected micrographs at $0,3,9$, and $12 \mathrm{~h}$ are shown. (C) Matrigel invasiveness in HSC-2 cells in the presence or absence of $1.0 \mu \mathrm{M}$ AG1478 was analyzed as described in the Materials and Methods. (D-F) The effects of U0126 on cell proliferation, motility, and invasion. The same experiments as in (A-C) were performed in the presence of $1.0 \mu \mathrm{M}$ U0126 (D), $10.0 \mu \mathrm{M}$ U0126 (E and F). DMSO was used for control treatment. Representative micrographs are shown. $*, \mathrm{P}<0.005$.

Supplemental Fig. 6. The effects of the p38 MAPK inhibitor SB203508 on cell proliferation, motility and invasion of HSC-2 cells. (A) Cell proliferation with or without $1.0 \mu \mathrm{M}$ SB203508 was examined every other day for 6 days. (B) Analysis of cell motility by wound healing assay in the presence or absence of $10.0 \mu \mathrm{M}$ SB203508. (C) Matrigel invasiveness in the presence or absence of $10.0 \mu \mathrm{M}$ SB203508. 
A

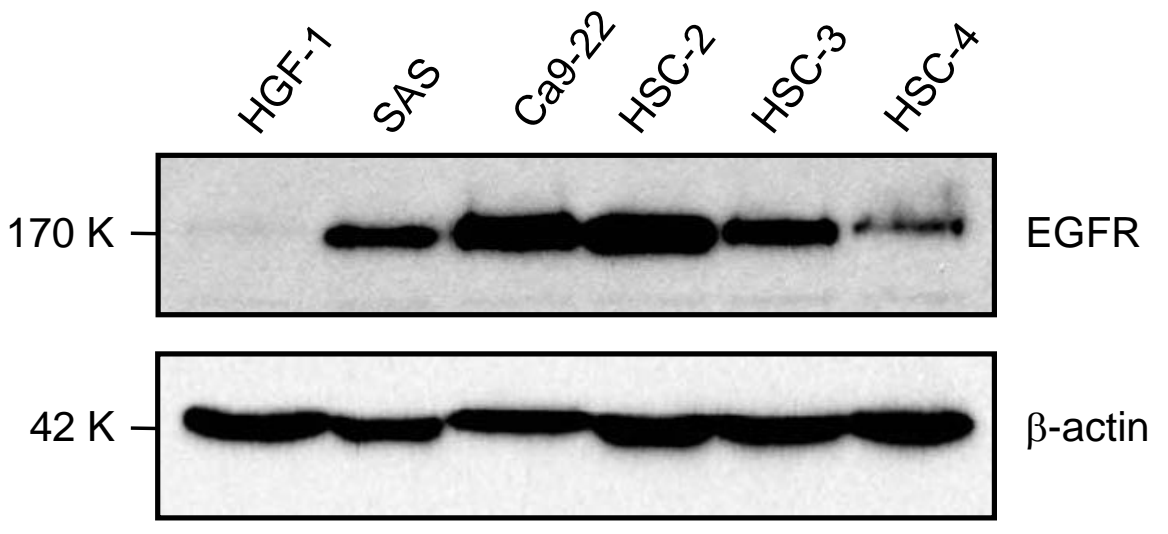

B

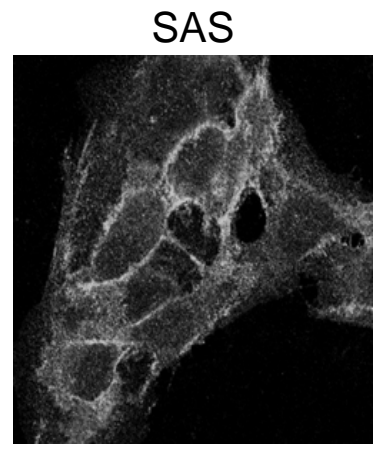

HSC-2

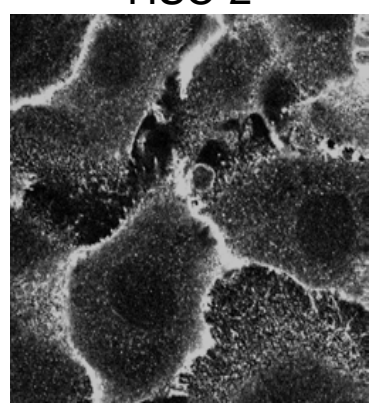

C

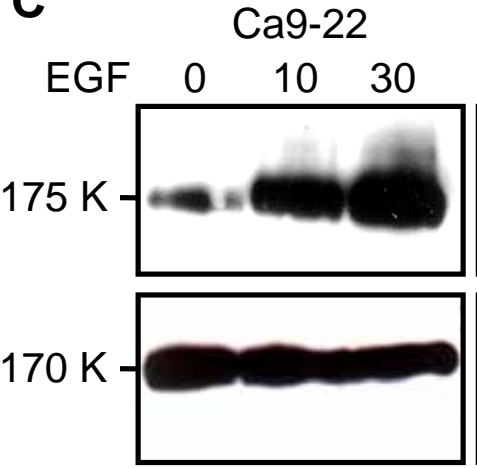

HSC-3

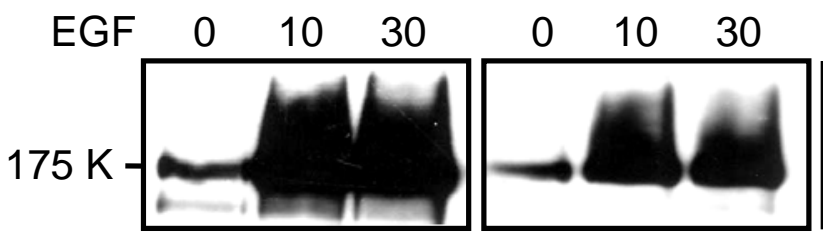

HSC-3

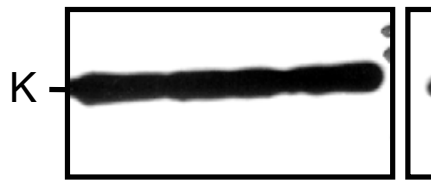

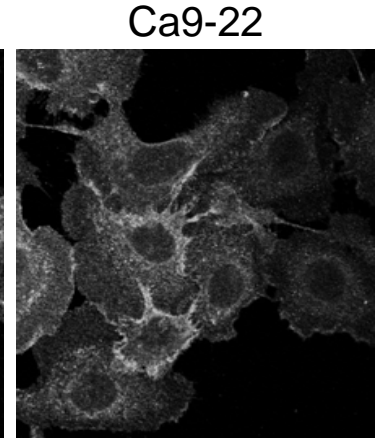

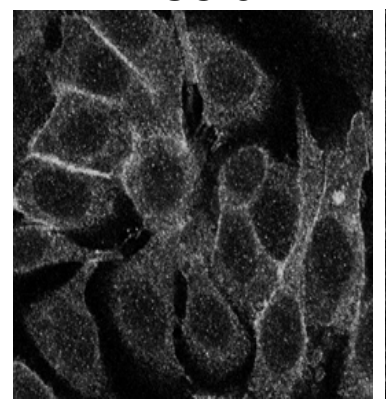

SAS HSC-2
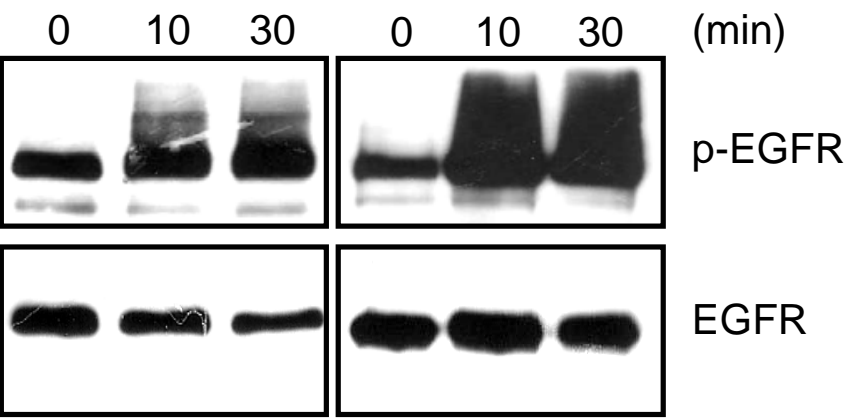

EGFR

A431

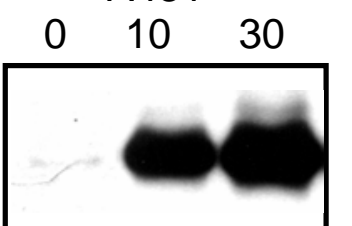

(min)

p-EGFR

EGFR 
A HSC-2

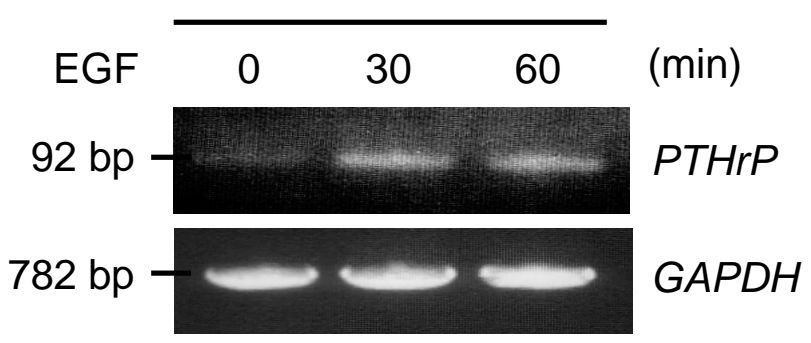

B

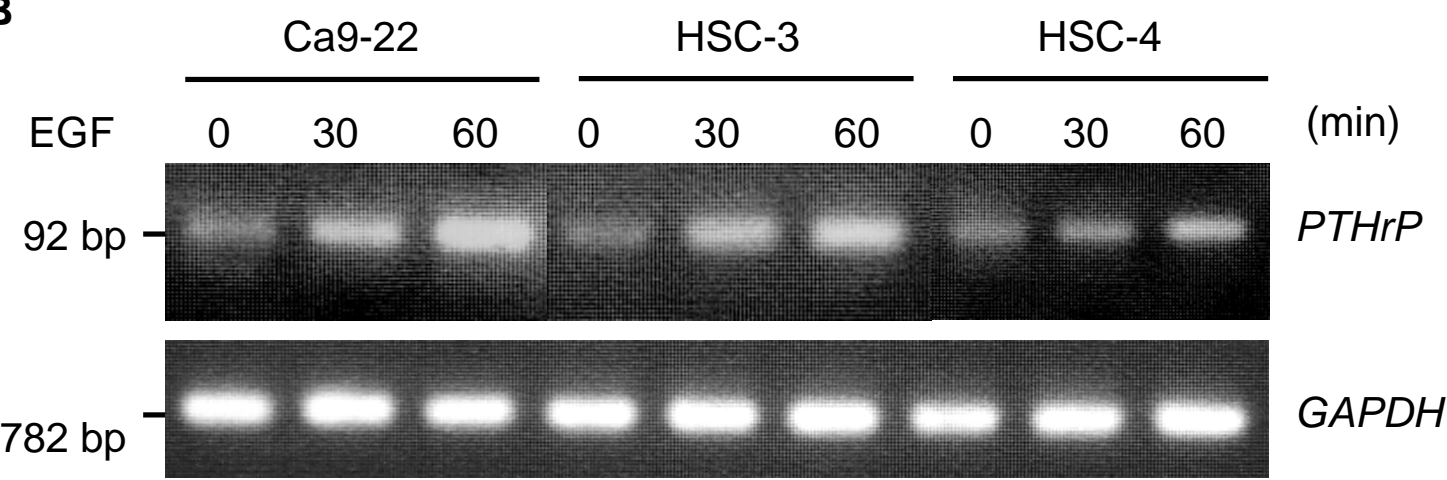

C

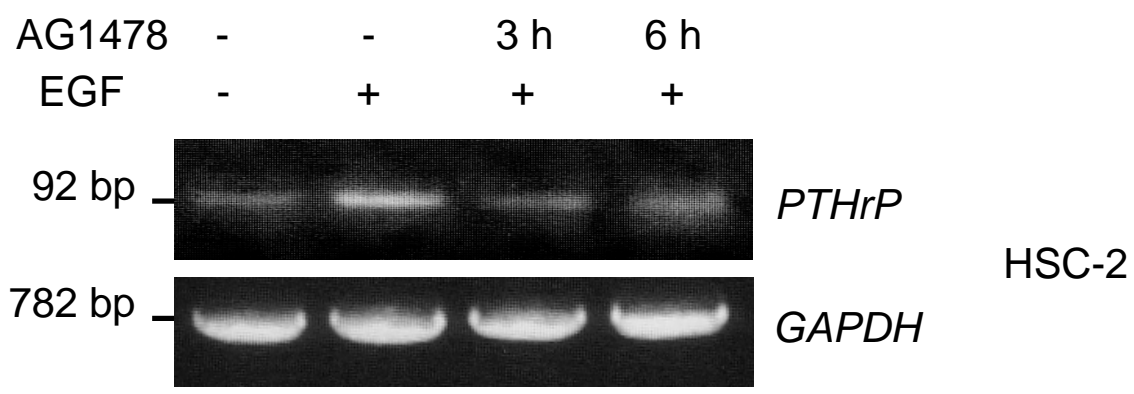

D

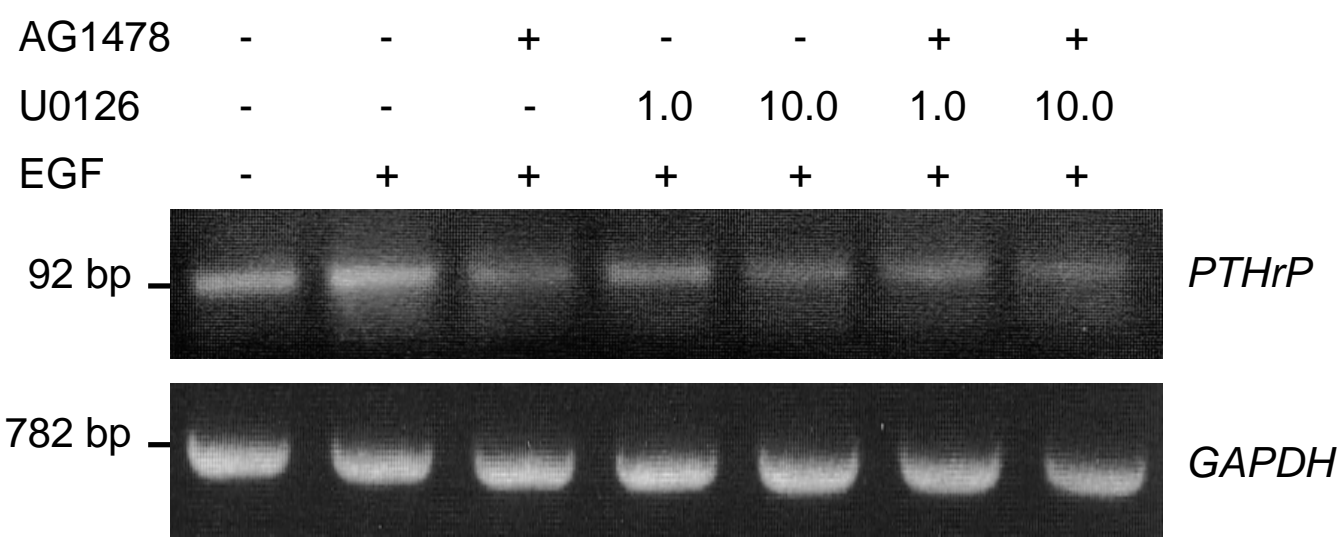

HSC-2 
A

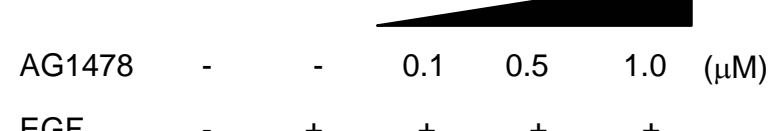

EGF
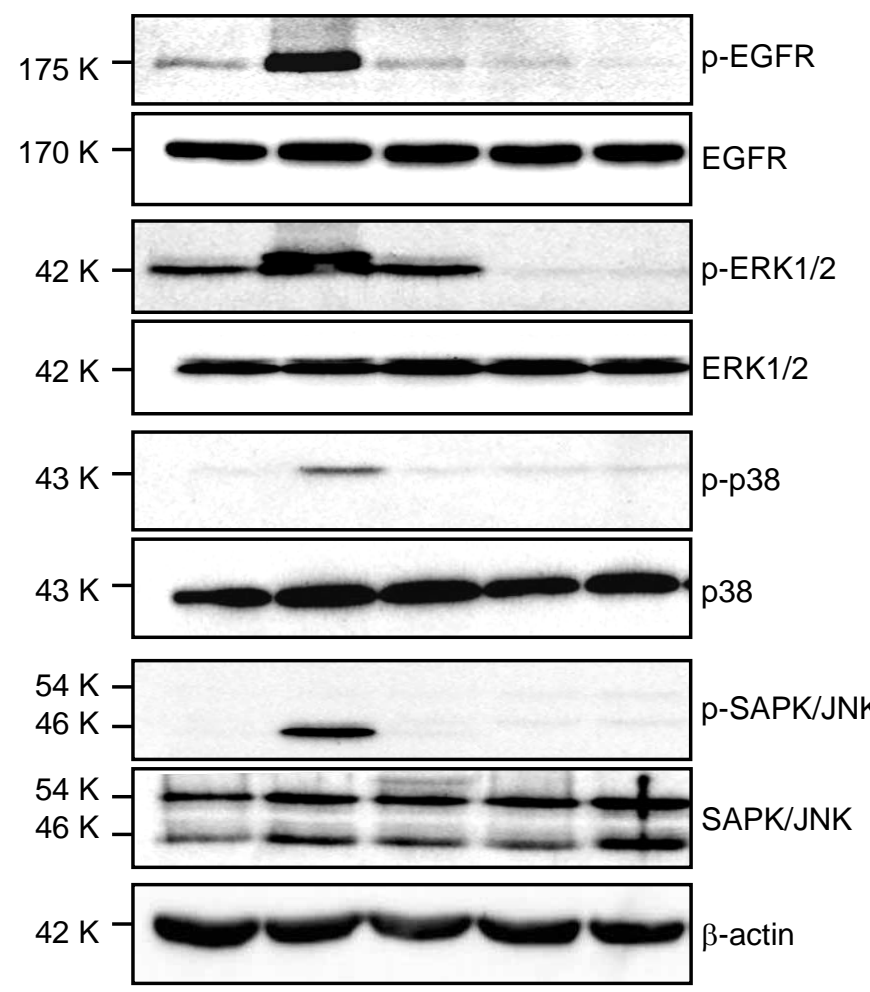

C

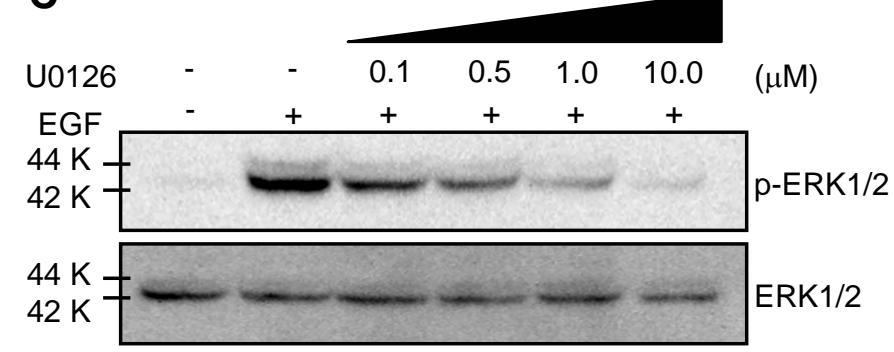

B
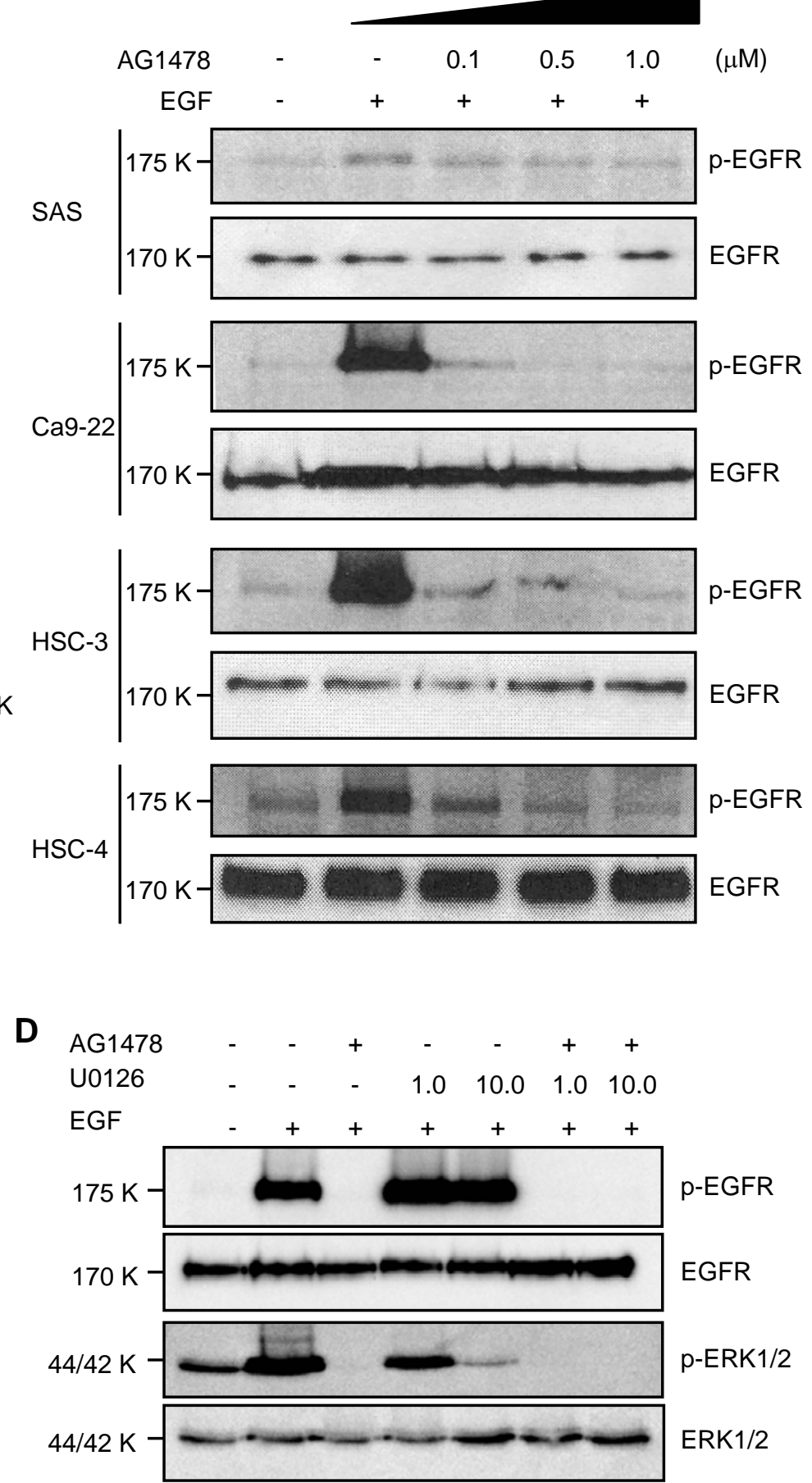
A

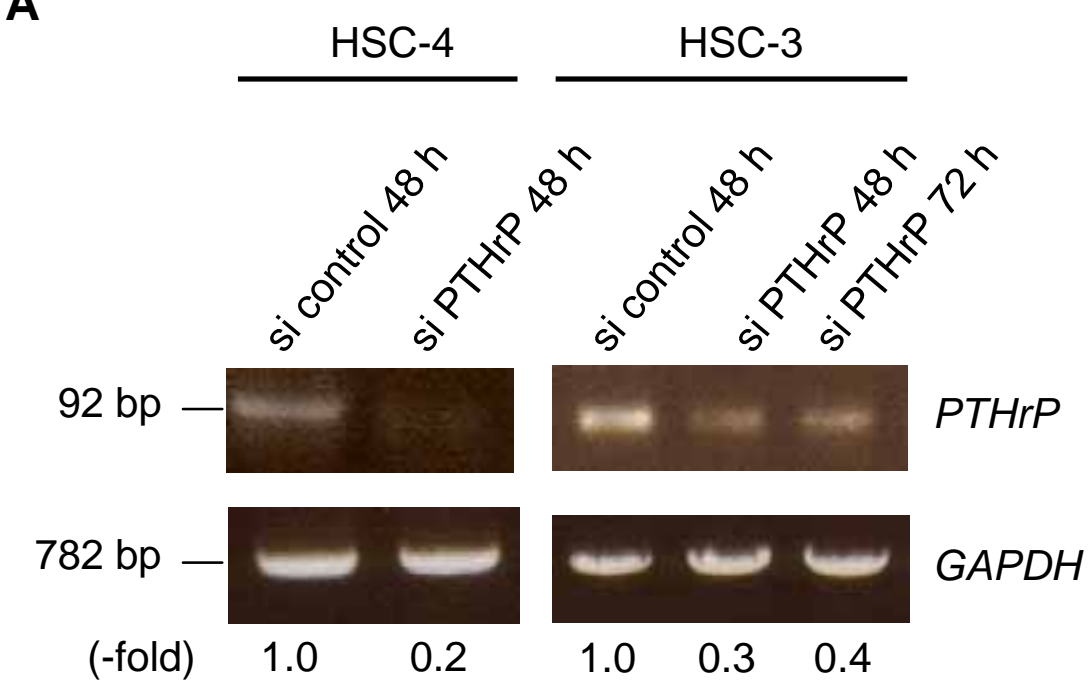

B

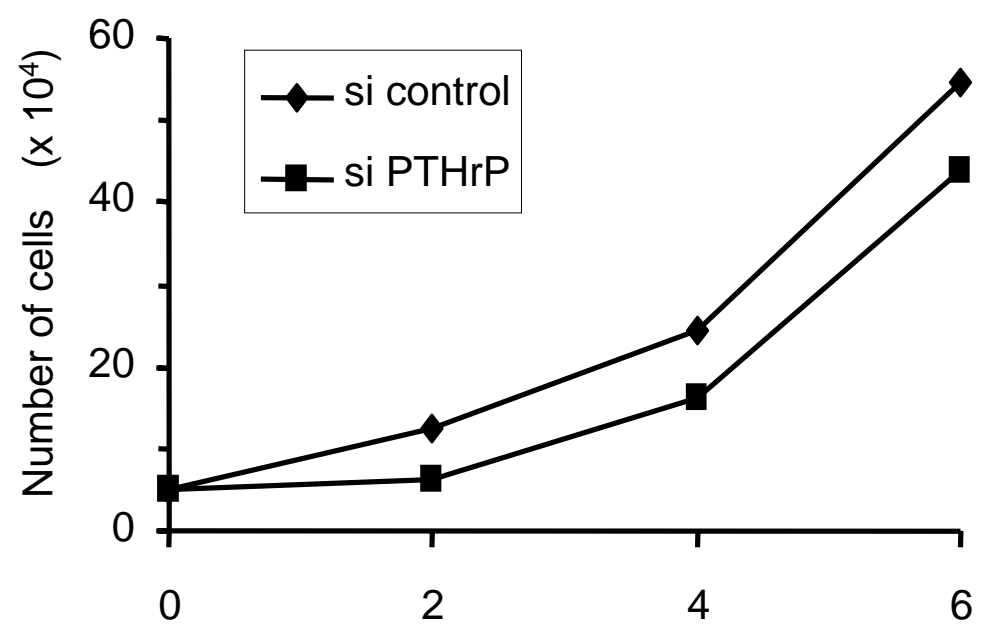

C

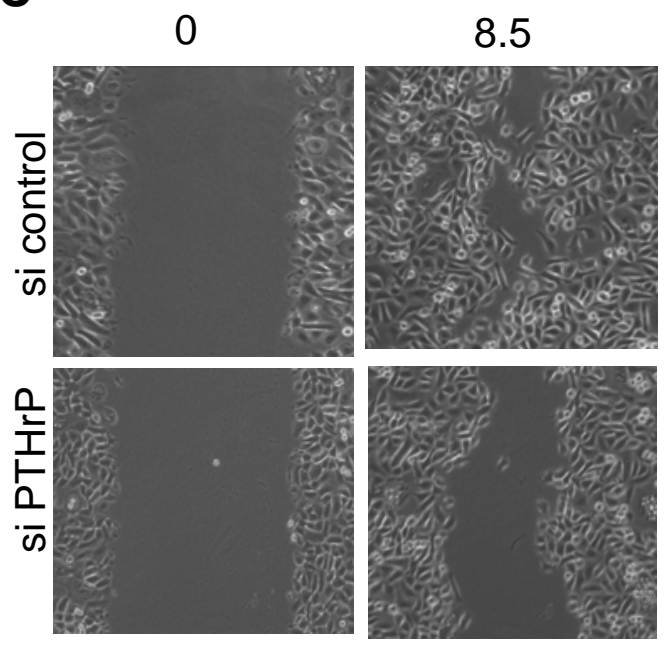

D

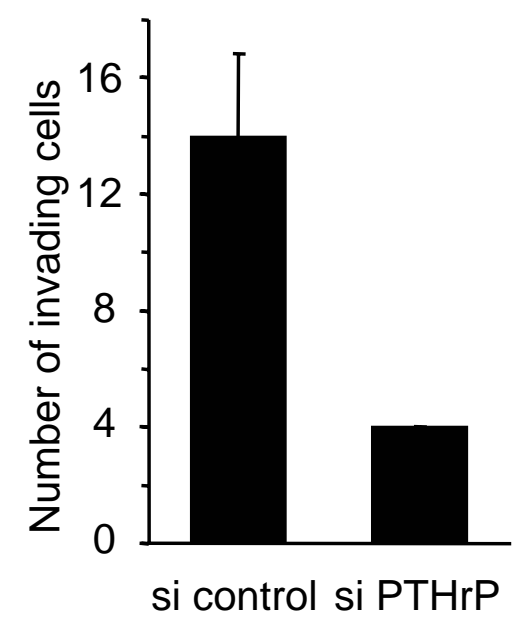


A
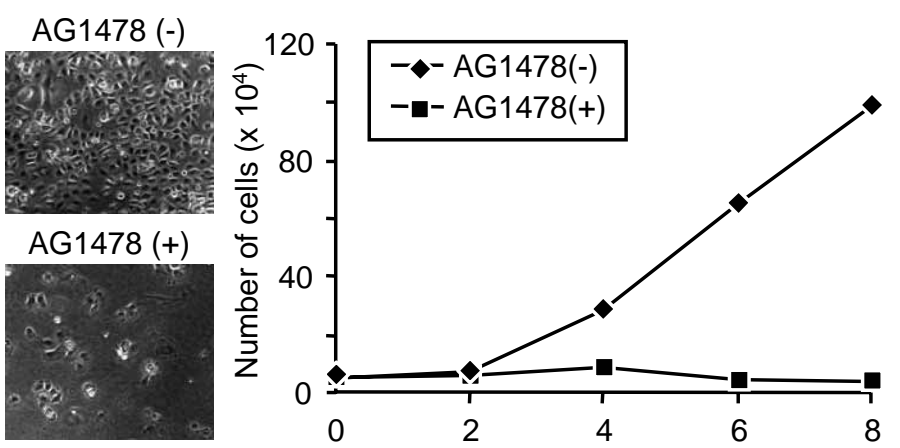

B

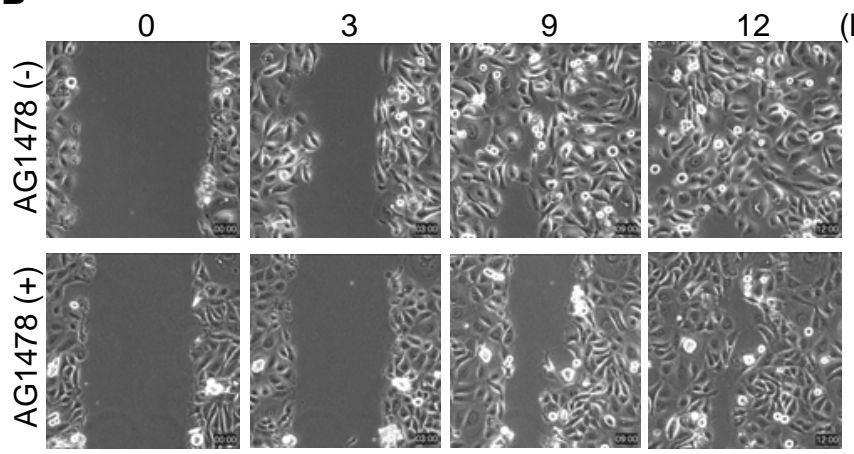

C
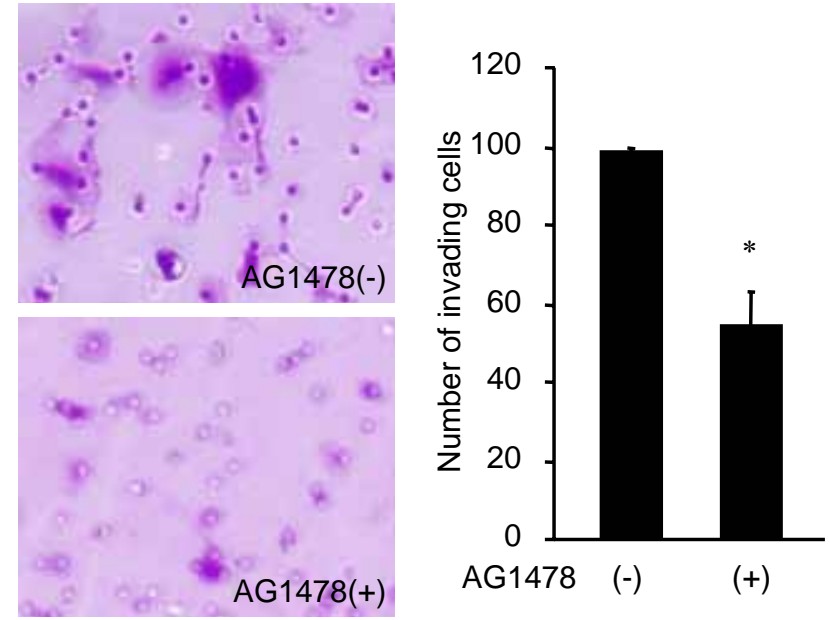

D

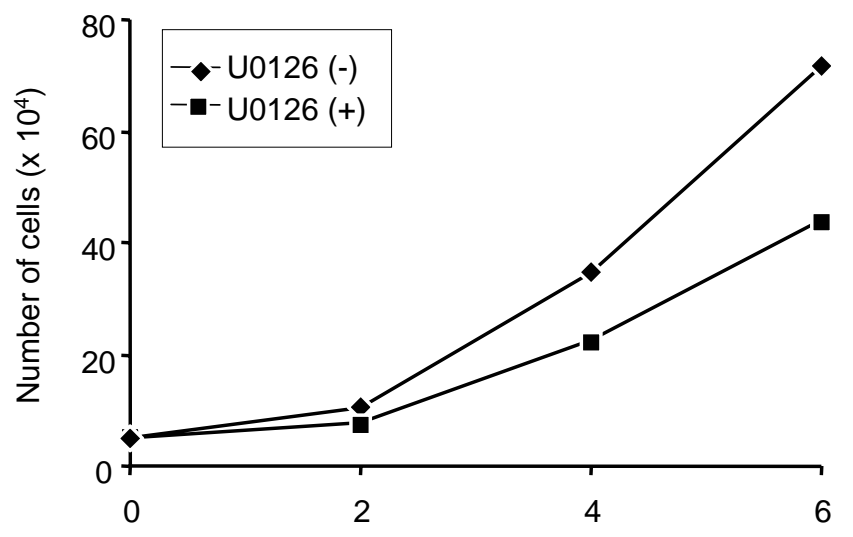

E
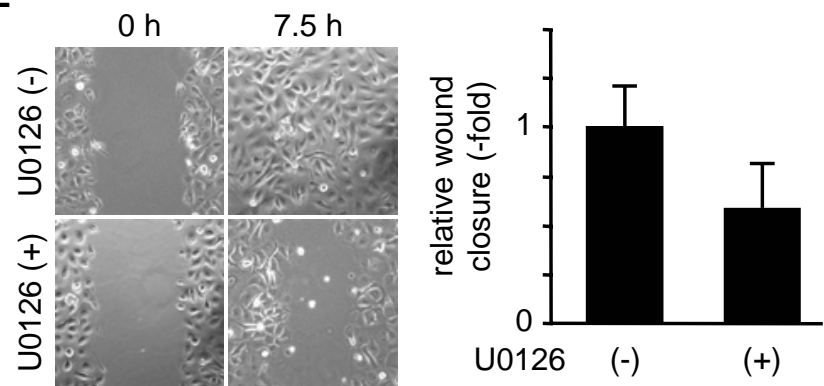

$\mathbf{F}$
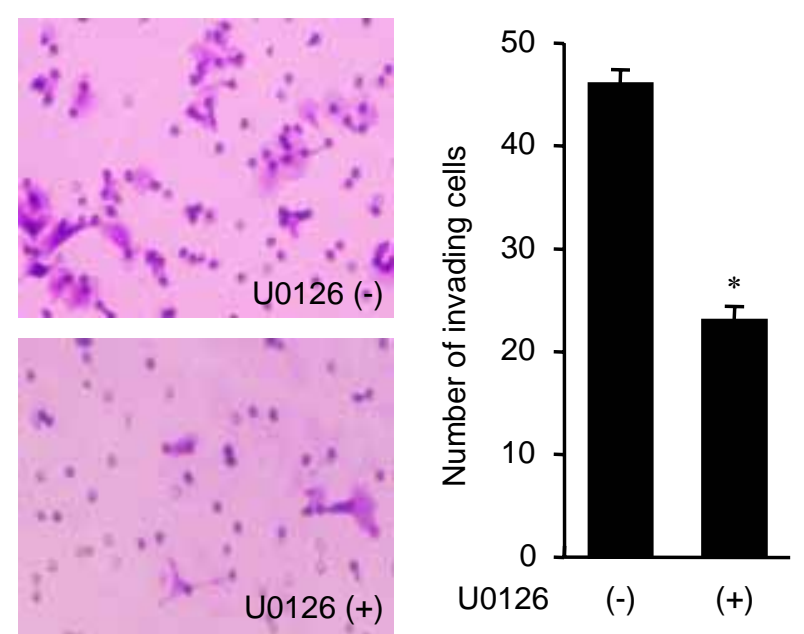

Supplemental Figure 5, Yamada et. al. 
A

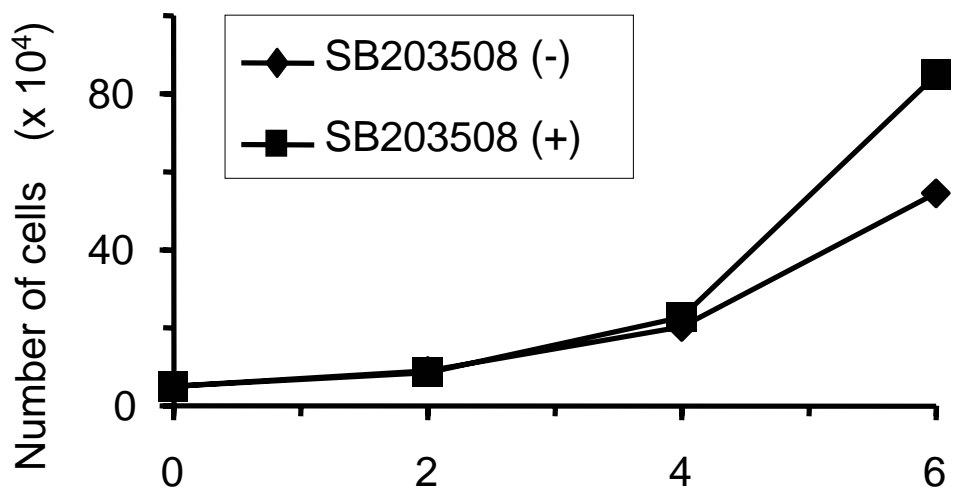

B

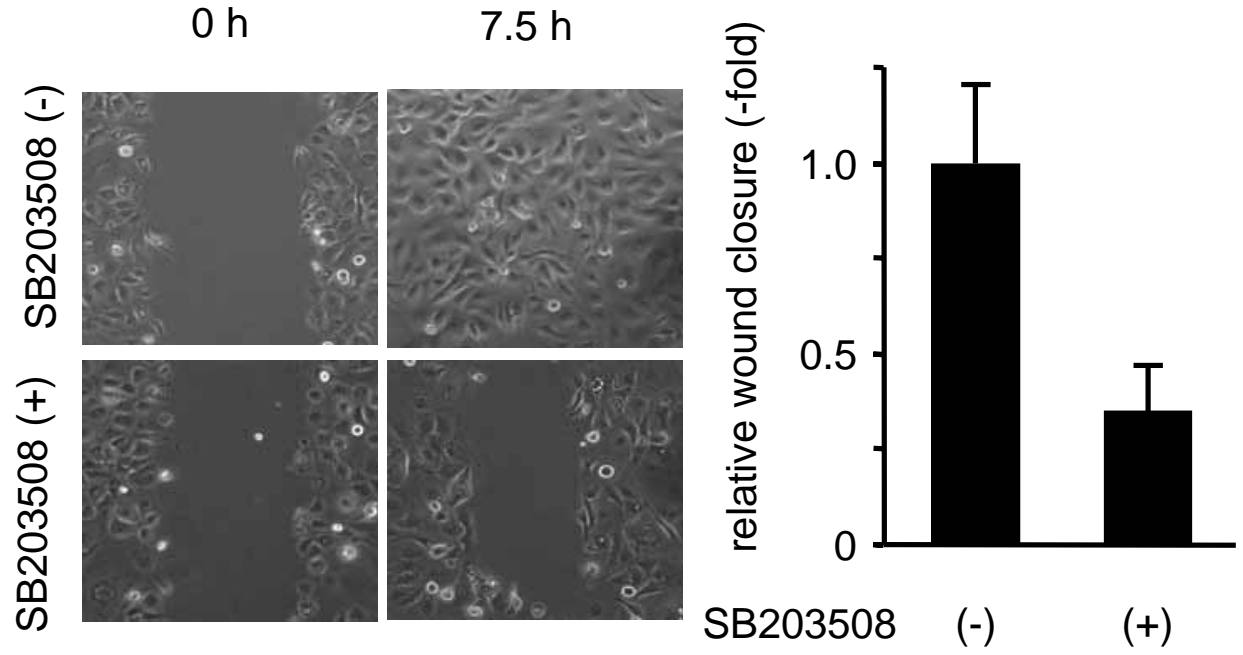

C

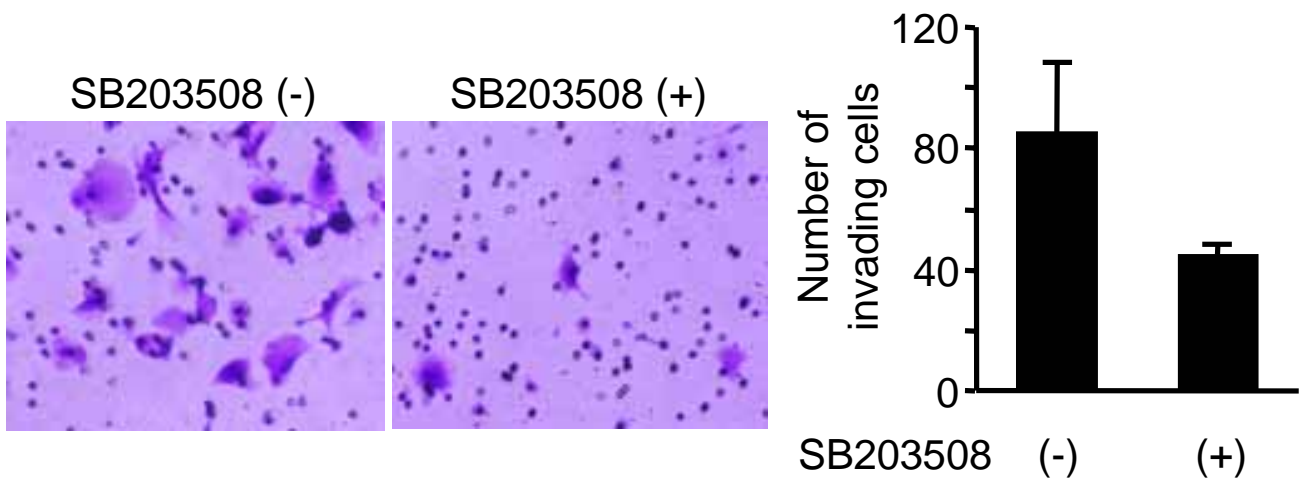

Supplemental Figure 6, Yamada et. al. 